International Journal of Engineering \&Technology, $7(4.24)(2018) 167-171$
International Journal of Engineering \& Technology
SPC
Website: www.sciencepubco.com/index.php/IJET
Research paper

\title{
Power Quality Enhancement by Integrating Distributed Generation in Distribution System
}

\author{
Mr. Rajesh Kumar Samala ${ }^{1 *}$, Dr. K Mercy Rosalina ${ }^{2}$ \\ ${ }^{1}$ Department of Electrical and Electronics Engineering, VFSTR (Deemed to be University), Guntur, 522213, INDIA. \\ ${ }^{21}$ Department of Electrical and Electronics Engineering, VFSTR (Deemed to be University), Guntur, 522213, INDIA. \\ *Corresponding author E-mail: rajeshkumarsamala143@gmail.com
}

\begin{abstract}
This research is to enhance the quality of power by reduce real power loss in distribution system and enables voltage profile enhancement at each bus. This will achieve by integrating Distributed Generation (DG) in optimal place with suitable size. In order to overcome the disadvantage of sluggish convergence of conventional algorithms the BAT Algorithm (BA) is used. In this paper the week buses are finding by using Backward/Forward (BW/FW) sweep approach based on real power loss. Later by using BA approach determination of optimal capacity and location will be done. This optimal size and location will leads to great minimization in real power los s and improvement of voltage at each bus. In this research the wind energy and Photo Voltaic (PV) energies are consider as DGs. This research is to determine the advantage of the proposed analysis on IEEE-69 radial bus using MATLAB software. The results were evaluated with the GSA approach existing in literature. Finally simulation outcomes prove that the proposed approach performance is superior in enhancing the power quality by optimal placement of DG and capacity of the DG.
\end{abstract}

Keywords: Backward/Forward (BW/FW) sweep analysis; BAT Algorithm (BA); Voltage profile; Active power loss.

\section{Introduction}

One of the most advantageous methods for minimizing something undesirable losses in distribution systems is to introducing DG's in the existing distribution systems [1]. The DG integration has practical advantages in photovoltaic, wind, gas turbine, geothermal, biomass and fuel cells. The technical benefits include voltage profile improvement, active power loss minimization; improve reliability of the system, etc. [2] [3]. All the benefits will achieve by integrating DG at optimal place with capacity. Improper DG integration in the network will lead to increase in power loss. [46]. However, the assignment is to enhance the network power quality by integrating the suitable DG size and site in network is not so easy [7].

Conventionally, the mixed integer linear program, Genetic Algorithm (GA), Tabu Search (TS), Particle Swarm Optimization (PSO) approach, direct search algorithm and Ant Colony Optimization (ACO) algorithms were used for analyse the proper DG capacity and place. In those research papers while locating DGs importance is given mostly on the minimization of active power loss. Some authors have illustrated to improve the voltage of the system also [8-10].

\section{Recent Research work:}

Most of research works are previously existed in literature survey which is based on proper place and capacity of DG in the system. Some of the works are reviewed here.
Satish Kansal et al. [11] presented a technique for proper location of various types of DGs. The proper site and capacity of DGs was used to reducing the active power loss. Various types of DGs providing real and reactive power at various buses have been considered in their presented technique. The Particle Swarm Optimization (PSO) approach has utilized to determine proper place of DGs. The outcomes found from the PSO approach have been evaluated with the analytical technique outcomes. Their presented technique was simulated on IEEE -33 and IEEE - 69 networks.

Banaja Mohanty et al. [12] have presented a Teaching Learning Based Optimization (TLBO) approach to determine the proper DG capacity and site. The proper site and capacity of DG was evaluated by having Voltage Stability Index (VSI) as an objective function. The advantage of their presented technique has been illustrated by evaluating the outcomes of GA and PSO techniques. Evaluation has completed by utilizing network outcomes like the active power loss and voltage. In their research, IEEE - 33 and IEEE - 69 buses were considered. 


\section{Radial Distribution System Power Flow Analysis:}

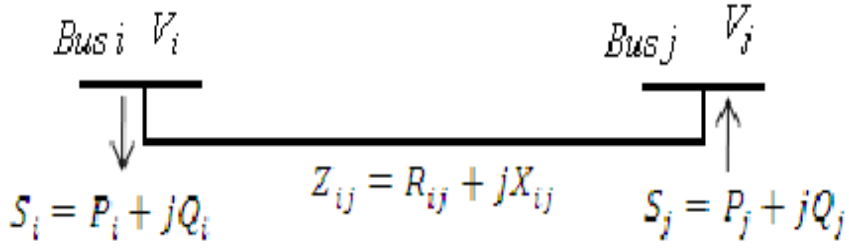

Fig.1: A two bus system single line diagram

This paper majorly focused on improvement of voltage profile waveform at every system bus by penetrating DGs into system for optimal capacity and optimal location in the given system. This objective function shows mathematically as:

$F=\left\{\begin{array}{c}\text { max.voltage at each bus }\left(f_{1}\right) \\ \text { min.active power } \operatorname{loss}\left(f_{2}\right) \\ \text { max.VSI(Voltage Stabilty Index })\left(f_{3}\right)\end{array}\right.$

The multi-objective optimization of above equation can be written individually as below:

\subsection{To find voltage profile improvement:}

$f_{1}=$ Voltage difference $=\sum_{n i=1}^{n}\left(\left|V_{r e f}\right|-\left|V_{n i}\right|\right)$

Where $V_{n i}$ is ni bus voltage and $V_{\text {ref }}$ is $1\left\llcorner 0^{0}\right.$ Per Unit.

\subsection{To find active power loss:}

$f_{2}=$ Active power loss in branch $i j=\left|I_{i j}\right|^{2} R_{i j}$

$$
=\frac{P_{e f f j}^{2}+Q_{e f f j}^{2}}{\left|V_{j}\right|^{2}} \times R_{i j}
$$

Where $I_{i j}$ is Current of branch $i j, R_{i j}$ is Resistance of branch $i j, P_{e f f j}$ is effective real power fed at bus $j, Q_{e f f j}$ is effective reactive power fed at bus $j, V_{j}$ is voltage at bus $j$.

$$
\begin{gathered}
P_{e f f j}=\frac{\left|V_{i}\right|\left|V_{j}\right|}{\left|Z_{i j}\right|} \cos \left(\varphi_{i j}-\delta_{i}+\delta_{j}\right)-\frac{\left|V_{j}\right|^{2}}{\left|Z_{i j}\right|} \cos \left(\varphi_{i j}\right) \\
Q_{e f f j}=\frac{\left|V_{i}\right|\left|V_{j}\right|}{\left|Z_{i j}\right|} \sin \left(\varphi_{i j}-\delta_{i}+\delta_{j}\right)-\frac{\left|V_{j}\right|^{2}}{\left|Z_{i j}\right|} \sin \left(\varphi_{i j}\right)
\end{gathered}
$$

Here $V_{i}$ is voltage at bus $i, V_{j}$ is voltage at bus $j, Z_{i j}$ is impedance of line $i-j, \varphi_{i j}$ is angle of line $i-j, \delta_{i}$ is angle of $V_{i}, \delta_{j}$ is angle of $V_{j}$.

\subsection{To find Voltage Stability Index (VSI):}

$$
\begin{gathered}
f_{3}=\operatorname{VSI}(j)=\left|V_{i}\right|^{4}-4\left[P_{\text {eff }, j} R_{i j}+Q_{\text {eff }, j} X_{i j}\right]\left|V_{i}\right|^{2}- \\
4\left[\left(P-P_{\text {eff }, j}\right) X_{i j}+\left(Q-Q_{\text {eff }, j}\right) R_{i j}\right]^{2}
\end{gathered}
$$

Where $V_{i}$ is voltage at bus $i, P_{e f f j}$ is effective active power fed at bus $j, R_{i j}$ is Resistance of branch $i j, Q_{e f f j}$ is effective reactive power fed at bus $j, X_{i j}$ is Reactance of branch $i j, P$ and $Q$ are the active and reactive power.

Low VSI value will lead the system instable. Because of this reason it is required to find the minimum VSI point in the system.

$$
\min (\operatorname{VSI}(j))=\left(\frac{1}{\operatorname{VSI}(j)}\right) ; j=\{1,2, \ldots, \mathrm{N}\}
$$

\subsection{Voltage Constraint:}

The voltage tolerance range for all buses is as follows:

$V_{\min } \leq V_{n i} \leq V_{\max }$

Where, $V_{\min }$ is minimum voltage, $V_{\max }$ is maximum voltage, $V_{n i}$ is voltage at bus $n i$

\subsection{Real Power loss constraint:}

$P L_{\text {withoutDG }} \geq P L_{\text {withDG }}$

Where, $P L_{\text {without } D G}$ is without DG power loss, $P L_{\text {with } D G}$ is with DG power loss.

\subsection{DG Constraint:}

$S^{d g}{ }_{\min } \leq S^{d g}{ }_{n i} \leq S^{d g}{ }_{\max }$

Where, $S^{d g}{ }_{\text {min }}$ is minimum apparent power at bus $n i, S^{d g}{ }_{\text {max }}$ is maximum apparent power at bus $n i, S_{n i}^{d g}$ is apparent power at bus $n i$.

\section{Load Flow Analysis:}

IEEE-69 radial distribution network with single slack bus and remaining load buses. Forward/ Backward sweep technique is using for power flow analysis. This method has two processes. In the first process the voltage at each bus is calculated and check for tolerance using backward sweep. Initially backward sweep, Initiates from the termination bus. Later forward sweep, Initiates from Initial bus. The base value of voltage is $12.66 \mathrm{KV}$ and base value of power is 100 MVA. 0.0001p.u is the tolerance.

\subsection{Forward/Backward sweep approach:}

1- Step: Consider line resistance and reactance data and bus data

2- Step: Set base values for power and voltage

3- Step: Compute per unit value of impedance and load 
4- Step: Start backward sweep from termination bus to initial bus to determine every bus voltage and active \&reactive power loss

5- Step: Start forward sweep to determine every bus voltage and active and reactive power loss

6- Step: After performing backward sweep, convergence should be checked.

$V_{\text {calculated }}-V_{\text {specified }}<\varepsilon$, here: $\varepsilon$ is tolerance

7-Step: If power flow not converged, repeat 5-Step and 6-

Step, else proceed to 8-Step

8- Step: Note outcomes of voltage at every bus and active power loss

9- Step: Stop

\section{Bat Algorithm}

Bat algorithm is using to minimize active power loss and improvement of voltage by proper DG capacity and site. The load flow means real and reactive power; voltage and the loss of real power have been found with the help of the backward/forward sweep approach. So the maximum real power loss and VSI bus and the consistent affecting values are obtained with the help of the Bat algorithm. [13].

a) It is clear that the bats are capable to differentiate detachment of pray, environmental complication and dissimilarity in the existing pray/food in the search course in different mysterious methods by echolocation possessions.

b) $\mathrm{A} \mathrm{k}^{\text {th }}$ Bat fly randomly through position as $\mathrm{x}_{\mathrm{k}}$, velocity as $\mathrm{v}_{\mathrm{k}}$, frequency as $\mathrm{f}_{\min }$ but through changeable wavelength as $\mathrm{k}_{\mathrm{k}}$ and echo loudness as $\mathrm{A}_{0}$ to investigate pray/victim. Micro-bats encompass a capacity to control frequency of the discharge echo pulses and pulse rate discharge out of $r \varepsilon[0,1]$ along with the detachment of their pray/food.

c) The echo pulse loudness should be diverse as dropping among diminished detachment of the food, i.e. from great $\mathrm{A}_{0}$ to a smallest value $\mathrm{A}_{\min }$ (at pray/food position) [14].

Here, the bat stimulated approach was used to obtain the most optimal DG capacity and sit. Primarily the populace dimension, dynamic and reactive power limitations are initialized and randomly generated the bus numbers for evaluating the objective function. The objective task of the projected method is minimization of loss of power, VSI and maximizing the voltage.
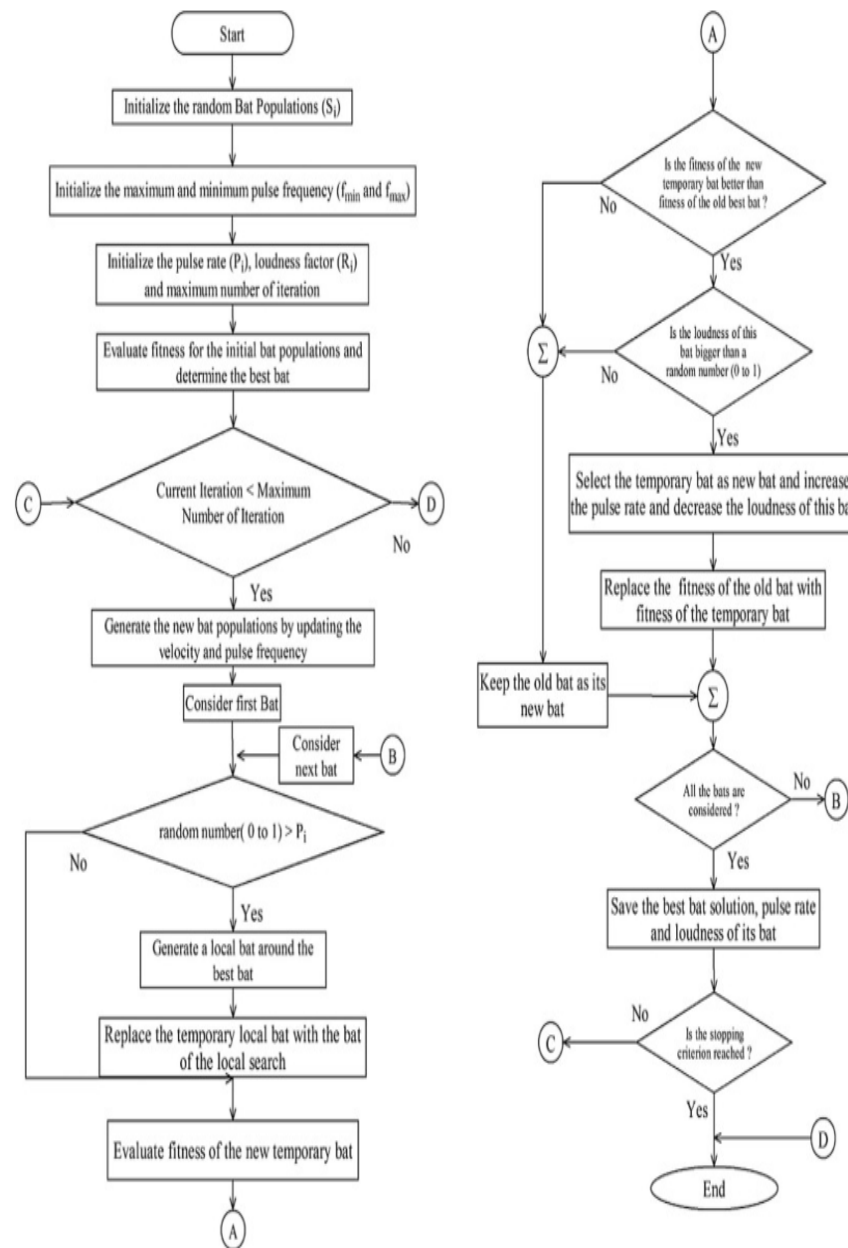

Select the temporary bat as new bat and increase the pulse rate and derease the loudness of this br
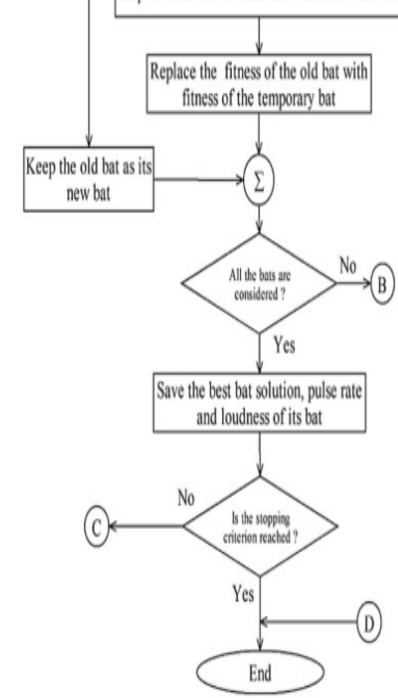

Fig. 2: Flow chart of proposed Bat algorithm technique

\section{IEEE-69 Radial Distribution System}

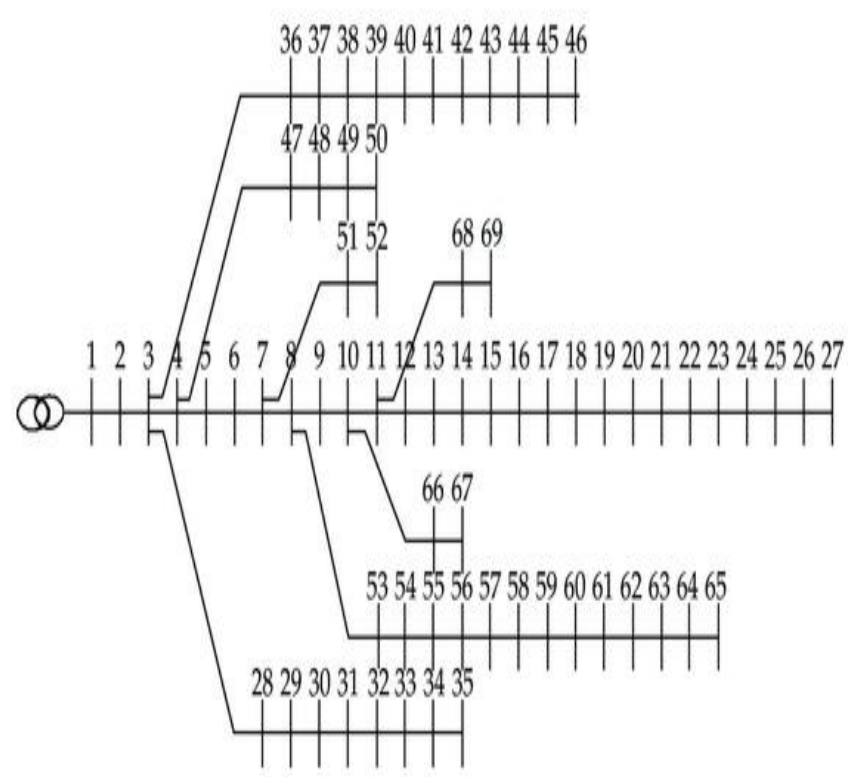

Fig. 3: IEEE-69 Radial Distribution System 


\section{Results}

The performance results of the BW/FW sweep analysis before DG placement, GSA analysis on load condition on IEEE - 69 bus is in table.1.

Table.1: Optimal location and capacity of dg using GSA method on IEEE-69 bus

\begin{tabular}{|c|c|c|c|c|c|c|c|c|}
\hline \multirow{3}{*}{$\begin{array}{l}\text { Bu } \\
\text { s } \\
\text { No }\end{array}$} & \multirow{3}{*}{$\begin{array}{l}\text { Nor- } \\
\text { mal } \\
\text { Power } \\
\text { Loss } \\
(k W)\end{array}$} & \multicolumn{2}{|c|}{$\begin{array}{l}\text { Power loss } \\
(k W)\end{array}$} & \multirow{3}{*}{$\begin{array}{l}\% \mathrm{Re}- \\
\text { duction }\end{array}$} & \multirow{2}{*}{\multicolumn{2}{|c|}{$\begin{array}{l}\text { DG ca- } \\
\text { pacity } \\
(k W)\end{array}$}} & \multirow{2}{*}{\multicolumn{2}{|c|}{$\begin{array}{l}\text { Optimal } \\
\text { bus con- } \\
\text { nected } \\
\text { for DG }\end{array}$}} \\
\hline & & \multirow{2}{*}{$\begin{array}{l}\text { Load } \\
\text { Pow- } \\
\text { er } \\
\text { Loss }\end{array}$} & \multirow{2}{*}{$\begin{array}{l}\text { GSA } \\
\text { Pow- } \\
\text { er } \\
\text { Loss }\end{array}$} & & & & & \\
\hline & & & & & $P V$ & $\begin{array}{l}W \\
T\end{array}$ & $\begin{array}{l}P \\
V\end{array}$ & $\begin{array}{l}W \\
T\end{array}$ \\
\hline \multirow{4}{*}{69} & \multirow{4}{*}{237.9} & 241.4 & 226.7 & 6.1 & 12 & $\begin{array}{l}20 \\
9\end{array}$ & 24 & 26 \\
\hline & & 238.2 & 224.9 & 5.5 & 85 & $\begin{array}{l}15 \\
8\end{array}$ & 54 & 19 \\
\hline & & 386.3 & 274.8 & 28.8 & $\begin{array}{l}10 \\
0\end{array}$ & $\begin{array}{l}19 \\
6\end{array}$ & 53 & 68 \\
\hline & & 261.2 & 193.4 & 25.9 & 60 & $\begin{array}{l}20 \\
4\end{array}$ & 61 & 58 \\
\hline
\end{tabular}

The performance results of the BW/FW sweep analysis before DG placement, BAT analysis on load condition on IEEE - 69 bus is in table. 2 .

Table.2: Optimal location and capacity of dg using BAT method on IEEE-69 bus

\begin{tabular}{|c|c|c|c|c|c|c|c|c|}
\hline \multirow{3}{*}{$\begin{array}{l}\text { Bu } \\
\text { s } \\
\text { No }\end{array}$} & \multirow{3}{*}{$\begin{array}{l}\text { Nor- } \\
\text { mal } \\
\text { Power } \\
\text { Loss } \\
(k W)\end{array}$} & \multicolumn{2}{|c|}{$\begin{array}{l}\text { Power loss } \\
(\mathrm{kW})\end{array}$} & \multirow{3}{*}{$\begin{array}{l}\% \mathrm{Re}- \\
\text { duction }\end{array}$} & \multirow{2}{*}{\multicolumn{2}{|c|}{$\begin{array}{l}\text { DG ca- } \\
\text { pacity } \\
(k W)\end{array}$}} & \multirow{2}{*}{\multicolumn{2}{|c|}{$\begin{array}{l}\text { Optimal } \\
\text { bus con- } \\
\text { nected } \\
\text { for DG }\end{array}$}} \\
\hline & & \multirow{2}{*}{$\begin{array}{l}\text { Load } \\
\text { Pow- } \\
\text { er } \\
\text { Loss }\end{array}$} & \multirow{2}{*}{$\begin{array}{l}\text { GSA } \\
\text { Pow- } \\
\text { er } \\
\text { Loss }\end{array}$} & & & & & \\
\hline & & & & & $P V$ & $\begin{array}{l}W \\
T\end{array}$ & $\begin{array}{l}P \\
\boldsymbol{V}\end{array}$ & $\begin{array}{l}W \\
T\end{array}$ \\
\hline \multirow{4}{*}{69} & \multirow{4}{*}{237.9} & 241.4 & 226.5 & 6.1 & 12 & $\begin{array}{l}20 \\
5\end{array}$ & 20 & 20 \\
\hline & & 238.2 & 232.6 & 2.3 & 85 & $\begin{array}{l}16 \\
0\end{array}$ & 48 & 24 \\
\hline & & 386.3 & 230.7 & 40 & $\begin{array}{l}10 \\
0\end{array}$ & $\begin{array}{l}15 \\
3\end{array}$ & 12 & 30 \\
\hline & & 261.2 & 227.2 & 13 & 60 & $\begin{array}{l}16 \\
5\end{array}$ & 12 & 14 \\
\hline
\end{tabular}

Initially, the vulnerable buses are identified on the maximum power loss and VSI. After the DG is placed and expected their capability by different methods. The above tables 1 and 2 prove that the different location and capacity of DG. In the table prove their power loss reducing and DG capacity. In the base condition, the loss is $237.9656 \mathrm{~kW}$. The performances are comparing by the BW/FW sweep method, GSA and BA technique. In the BA method, the base losses are reduced up to $224.867 \mathrm{~kW}$. The real power loss reduced percentage as associated to the base value is $41.79 \%$.
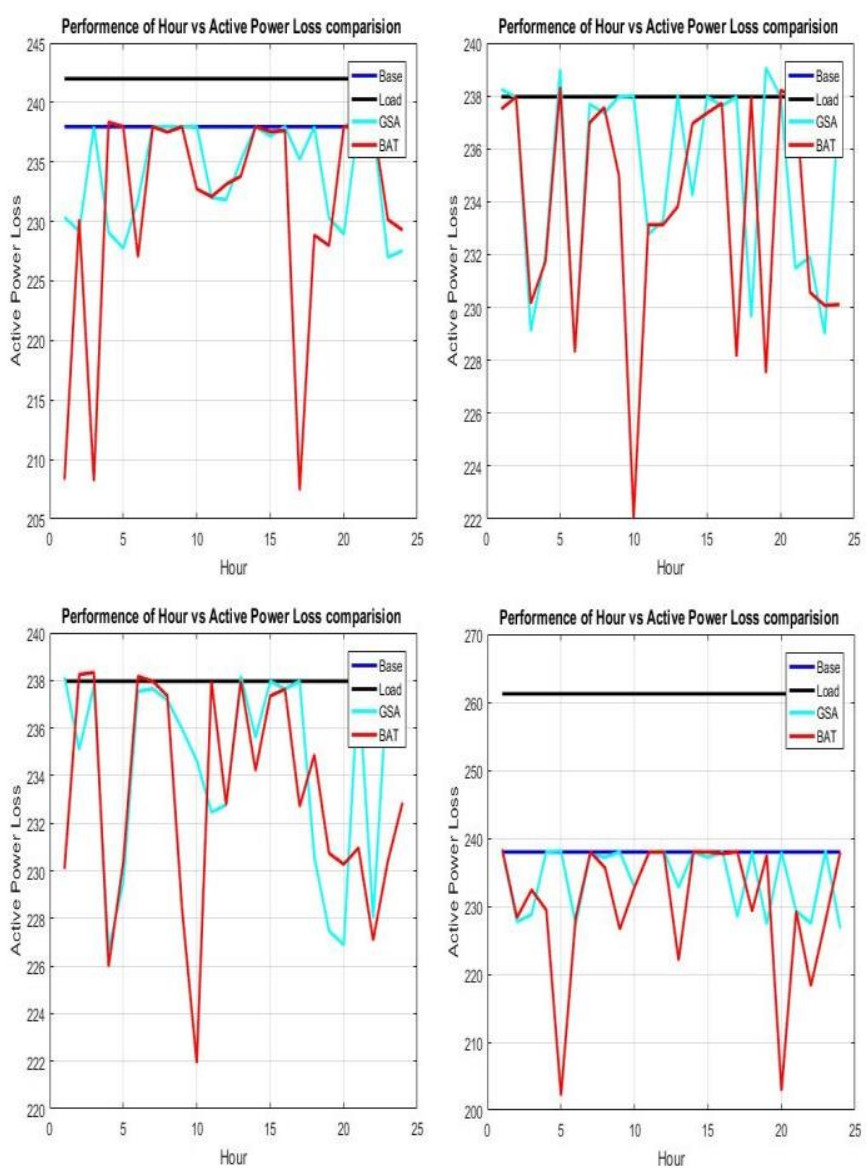

Fig. 4: Comparison Analysis of power loss using various methods when load added on (a) 20 (b) 22 (c) 24 and (d) 63 bus
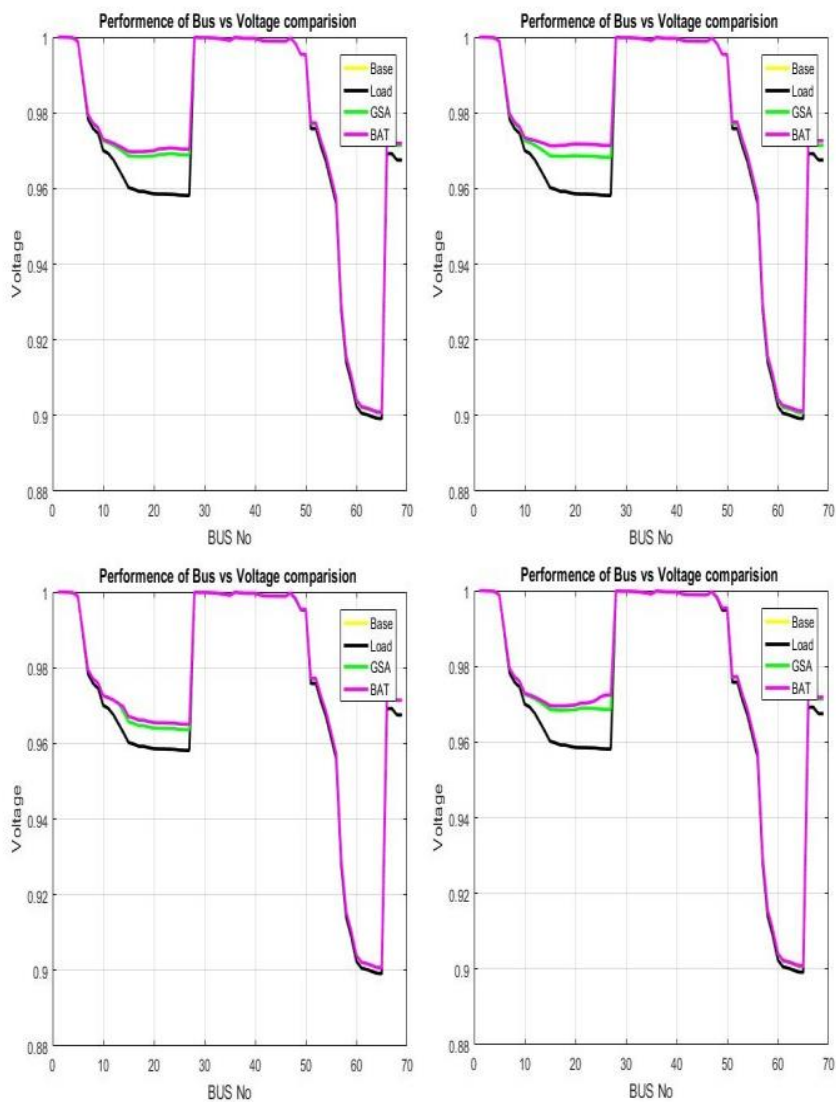

Fig. 5: Comparison Analysis of voltage using various methods when load added on (a) 31 (b) 37 (c) 48 and (d) 49 bus 


\section{Conclusion}

This paper firstly shows that the voltage profile from power flow analysis using BW/FW sweep analysis on IEEE-69 bus radial network. After that GSA and BA are utilized to determine proper place and capacity of the DG to enhance the power quality by optimize the voltage and reduce active power loss. These methods implemented on MATLAB/Simulink software under normal and loaded conditions. By the comparison of different algorithms it is clearly shown that the BA analysis is the efficient and effective power flow analysis for the radial power distribution networks.

\section{References}

[1] A.M. El-Zonkoly, "Optimal placement of multi-distributed generation units including different load models using particle swarm optimization", Swarm and Evolutionary Computation, Vol. 1, pp. 50-59, 2011.

[2] U. Sultana, Azhar B. Khairuddin, M.M. Aman, A.S. Mokhtar, N. Zareen, "A review of optimum DG placement based on minimization of power losses and voltage stability enhancement of distribution system", "Renewable and Sustainable Energy Reviews, Vol. 63, pp. 363-378, 2016.

[3] S.Chandrashekhar Reddy, P.V.N.Prasad, A.JayaLaxmi, "Reliability Improvement of Distribution system by Optimal Placement of DGs using PSO and Neural Network", In proceedings of International Conference on Computing, Electronics and Electrical Technologies [ICCEET], 2012.

[4] R.A. Jabr and B.C. Pal, "Ordinal optimisation approach for locating and sizing of distributed generation", IET Generation, Transmission, Distribution, Vol. 3, No. 8, pp. 713-723, 2009.

[5] Rashmi Priya, Surya Prakash, "Optimal Location and Sizing of Generator in Distributed Generation System", International Journal of Innovative Research in Electrical, Electronics, Instrumentation and Control Engineering Vol. 2, No. 3, March 2014.

[6] C. Nayanatara, J. Baskaran and D.P. Kothari, "Hybrid optimization implemented for distributed generation parameters in a power system network", Electrical Power and Energy Systems, Vol. 78, pp. 690-699, 2016.

[7] Juan Andrés Martín García and Antonio José Gil Mena, "Optimal distributed generation location and size using a modified teachinglearning based optimization algorithm", Electrical Power and Energy Systems, Vol. 50, pp. 65-75, 2013.

[8] M. Gomez-Gonzalez,A. López and F. Jurado, "Optimization of distributed generation systems using a new discrete PSO and OPF", Electric Power Systems Research, Vol. 84, pp. 174-180, 2012.

[9] Pavlos S. Georgilakis, and Nikos D. Hatziargyriou, "Optimal Distributed Generation Placement in Power Distribution Networks: Models, Methods, and Future Research", IEEE Transactions On Power Systems, Vol. 28, No. 3, August 2013.

[10] Prem Prakash, Dheeraj K. Khatod, "Optimal sizing and siting techniques for distributed generation in distribution systems: A review", Renewable and Sustainable Energy Reviews, Vol. 57, pp. 111-130, 2016.

[11] Satish Kansal, Vishal Kumar and Barjeev Tyagi, "Optimal placement of different type of DG sources in distribution networks", Electrical Power and Energy Systems, Vol. 53, pp.752760, 2013.

[12] Banaja Mohanty and Sasmita Tripathy, "A teaching learning based optimization technique for optimal location and size of DG in distribution network", Journal of Electrical Systems and Information Technology, Vol. 3, pp. 33-44, 2016.

[13] Sambariya, D.K. and Prasad, R., "Robust tuning of power system stabilizer for small signal stability enhancement using metaheuristic bat algorithm. International Journal of Electrical Power \& Energy Systems, 61, pp.229-238. 2014.

[14] Abd-Elazim SM, Ali ES, "Load frequency controller design via BAT algorithm for nonlinear interconnected power system", International Journal of Electrical Power \& Energy Systems, Vol. 77, pp. 166-77, 2016. 